2016-11-28

\title{
Grain-size distributions on high energy sandy beaches and their relation to wave dissipation
}

\section{Prodger, S}

http://hdl.handle.net/10026.1/8464

$10.1111 /$ sed.12353

Sedimentology

Wiley

All content in PEARL is protected by copyright law. Author manuscripts are made available in accordance with publisher policies. Please cite only the published version using the details provided on the item record or document. In the absence of an open licence (e.g. Creative Commons), permissions for further reuse of content should be sought from the publisher or author. 
Received Date : 31-Mar-2016

Revised Date : 27-Oct-2016

Accepted Date : 25-Nov-2016

Article type : Original Manuscript

\section{Grain-size distributions on high energy sandy beaches and their relation to wave dissipation}

Prodger, Sam ${ }^{1}$, Russell, Paul ${ }^{1}$ \& Davidson, Mark .

${ }^{1}$ School of Marine Science \& Engineering, Plymouth University, Plymouth, UK.

Corresponding author: sam.prodger@plymouth.ac.uk

Associate Editor - JP Walsh

Short Title - Grain size and sorting on high-energy beaches

This is an Accepted Article that has been peer-reviewed and approved for publication in the Sedimentology, but has yet to undergo copy-editing and proof correction. Please cite this article as an "Accepted Article"; doi: 10.1111/sed.12353

This article is protected by copyright. All rights reserved. 


\section{ABSTRACT}

Grain size and sorting represent two key parameters when characterising sediments or modelling beach morphology and sediment transport. Traditionally, an average value for grain size or sorting is often assumed for the entire area, determined from only a few sediment samples, ignoring any spatial (or temporal) variability in sediment characteristics. This contribution uses a data set of physical surface sediment samples from 53 beach locations around the south-west peninsula of the United Kingdom, in addition to bi-monthly, high spatial resolution (mean 240 samples) digital grain-size surveys from a high-energy, oceanic, sandy beach (Perranporth, North Cornwall). Systematic spatial variations in grain size and sorting were consistently observed in the seaward direction across the intertidal zone of sandy beaches, with grain sizes coarsening and sorting improving by up to $51.7 \%$ and $64.3 \%$, respectively. This variability was deterministically related to the time-averaged, antecedent-adjusted energy dissipated by breaking waves, with the observed maximum grain sizes and sorting values correlating with the location of peak wave energy dissipation $\left(r^{2}=0.998, p<0.01\right)$.

Keywords: Coastal sediments, digital grain size, energy dissipation, intertidal grain size, sandy beaches, sorting

\section{INTRODUCTION}

It has been well-documented that variability in beach sediments has an impact upon a number of nearshore processes, including sediment transport and morphological evolution. However, due to the time-consuming nature of sediment sampling and the subsequent laboratory analysis, it is often assumed that sediments remain spatially and temporally homogenous. This is despite a number of studies showing that beach sediments can vary

This article is protected by copyright. All rights reserved. 
over a number of scales; Bagnold (1941) found that the ripple crests were significantly coarser and better sorted than the troughs, which was supported by Doucette (2002) and Trembanis et al. (2004). On larger spatial scales, Abuodha (2003) found an increase in grain size between the dune and intertidal systems, with Warrick et al. (2009a) finding that the low tide terrace could be up to $70 \%$ coarser and considerably better sorted than the upper beach. Thornton et al. (2007) correlated an alongshore increase in wave height to increases in grain size and measurements made by Thorpe et al. (2014) described sediments found in active rip channels that were significantly coarser than those found on an adjacent intertidal bar.

When applying coastal models, the variability shown by these studies is often omitted and a grain size and sorting for the entire cross and alongshore extent of a beach is inferred from just one single sample. Although, modern advances to coastal models [for example, Xbeach (Roelvink et al., 2009) or Telemac (Hervouet \& Bates, 2000)] have enabled a degree of either spatial (or temporal) sediment tracking modules, the computational costs are often so expensive they are seldom enabled for modelling timescales longer than a few hours to days. Therefore, a quantifiable understanding of the variability exhibited by sandy sediments in a response to changes in the hydrodynamic conditions can aid these modelling efforts.

In order to improve the spatial resolution of sediment studies, traditionally demanding methods of collecting and analysing physical sediment samples are being replaced by advancements in semi-autonomous image processing to extract a grain size and sorting value from digital photographs of the beach surface. Gallagher et al. (2011) used the spatial autocorrelation method proposed by Rubin (2004) for estimating grain size and collected ca 1000 samples from a meso-tidal, high-energy beach at Truc Vert, France. These authors observed a general seaward increase in grain size across the intertidal zone, with sediments on the lower beach up to $0.24 \mathrm{~mm}(58 \%)$ coarser than the upper beach sediments; and also found localised coarsening in channels related to the faster flow speeds of rip currents. Gallagher et al. (2016) also found the same increase in grain size with increasing seaward This article is protected by copyright. All rights reserved. 
distance across the intertidal zone at Duck, North Carolina. Additionally, using a similar imaging set-up, Reniers et al. (2013) found that coarse sediments on a steep, micro-tidal beach (Monterey, California) correlated well with the position of the shore break, and although these predictions only covered a ten-day hindcast these authors were able to successfully model their observations. These studies all showed that sediment grain size is not homogenous, with significant variability possible across spatial scales from only a few millimetres up to kilometre scales. Thus far, studies of beach sediment characteristics have focussed on micro-tidal and meso-tidal coasts, with a lack of repeat field observations on macro-tidal beaches. Therefore, this paper investigates the observed spatial variability in sediment grain size and sorting using the high-energy, predominantly macro-tidal beaches around the south-west coast of the UK. This variability is related to the prevailing hydrodynamics and morphodynamics using a wave energy dissipation model.

\section{METHODOLOGY}

Physical sediment samples were collected from 53 separate beach sites around the southwest peninsula of the UK (Fig. 1) in April 2014. Samples were collected from the surface at three cross-shore positions that related to mean spring high, mid and low tide, alongside a RTK-GPS (accurate to $\pm 0.03 \mathrm{~m}$ ) beach profile. If the samples contained no clasts larger than $0.02 \mathrm{~m}$, the grain-size distributions were obtained using a settling tube approach. Sediment fall velocity, output from the settling tube, was converted to median grain size $\left(D_{50}\right)$ using the Ferguson \& Church (2004) equation, where $D_{50}$ is the median particle size by mass and sediment sorting is the standard deviation or spread of grain sizes around this median value, where:

$$
\sigma_{1}=\left(\frac{\emptyset_{84-} \varnothing_{16}}{4}\right)+\left(\frac{\emptyset_{95}-\emptyset_{5}}{6.6}\right) \quad \text { Equation (1) }
$$

This article is protected by copyright. All rights reserved. 
here, $\sigma_{1}$ is the sediment sorting and $\emptyset_{x}$ is the grain diameter (in phi units) at the cumulative percentile value of $x$. Each sample was passed through the settling tube on three occasions, with a $D_{50}$ value resulting from the average of these three tests. Samples containing clasts larger than $0.02 \mathrm{~m}$ were too large to be removed from the bottom of the settling tube and so were dried, passed through decreasing quarter-phi scale sieves by shaking for 15 minutes and then weighed, with grain-size statistics calculated using the logarithmic Folk \& Ward (1957) graphical measures.

Using physical samples, the spatial coverage is often limited to a few locations due to the time-consuming nature of dry sieving or settling. Therefore, a digital grain size (DGS) collection method was undertaken every other month (nine in total, mean interval 59 days) at Perranporth (Fig. 1, Red Square) on spring low tides from June 2014 to November 2015, with a minimum of 118, maximum of 302 and mean of 223 digital samples (surface photographs) collected each visit. Two digital cameras capable of capturing still images at 12 mega pixel resolution were mounted onto an RTK-GPS survey pole, one $0.02 \mathrm{~m}$ above the bed and one $0.15 \mathrm{~m}$ above the bed. Each camera was located inside a waterproof housing fitted with a macro-lens and LED lighting. The use of two cameras at different heights allowed both the sandy and any larger gravel/shell fractions (if present) to be sufficiently captured, with each image recorded with an associated GPS position (accurate to $\pm 0.03 \mathrm{~m})$. The geometric distortion caused by the addition of a macro lens was corrected using the standard Photoshop CC 2015 filter package (Evening, 2015). The digital samples had an average cross-shore spacing of $20 \mathrm{~m}$ and an average longshore spacing of $100 \mathrm{~m}$, covering an area of $550 \mathrm{~m}$ by $1200 \mathrm{~m}$. This study uses a DGS technique based upon the transferable wavelet method proposed by Buscombe (2013), rather than the more traditional spatial autocorrelation process (Barnard et al., 2007; Rubin et al., 2007; Warrick et al., 2009b). Before using the DGS in the field, a validation was performed by comparing digital estimates of grain size and sorting for 63 separate samples against results obtained by settling the same samples (Fig. 2). This validation included using one to twenty-five images

This article is protected by copyright. All rights reserved. 
of the same samples, with only minor increases in accuracy found by including additional images. As the correlation coefficient $\left(r^{2}\right)$ exceeded 0.95 for both grain size and sorting and the $95 \%$ confidence intervals of the digital grain-size results compared to settling were $0.0084 \mathrm{~mm}$ and $0.0064 \mathrm{~mm}$, respectively, the digital collection and processing was suitable for field deployment.

\section{RESULTS}

\subsection{Regional grain-size patterns}

The sediment samples collected from the surface at three-cross positions from 53 beach sites around the south-west (UK) peninsula, were physically analysed for $D_{50}$ and sediment sorting. South and east facing beach locations were typically coarser, poorer sorted and more compositionally immature than the north coast. Linked to the larger grain sizes and the smaller wave heights, beach morphology was more reflective, with a steeper slope and narrower intertidal zone.

Using the three samples from mean spring high, mid and low tide, 49 of the 53 sites showed an increase in grain size (Fig. 3A) and an improvement in sorting (Fig. 3B) with increasing seaward distance across the intertidal zone. Of the remaining four, the two south facing sites were composed of mixed sand and gravel, which are hydrodynamically different and tend to be coarser towards the upper beach (Horn \& Walton, 2007) or have significant grading (Buscombe \& Masselink, 2006). The two atypical north coast sites are situated immediately adjacent to river estuaries, which deposits mud and fine sand towards the base of the profiles. The minimum, mean and maximum percentage increase in grain size between the upper and lower beach samples was $4.3 \%, 19.1 \%$ and $53.1 \%$, respectively, and $2.6 \%, 17.6 \%$ and $46.6 \%$ for the associated improvement in sorting.

This article is protected by copyright. All rights reserved. 


\subsection{Local grain-size patterns}

The regional observations of cross-shore grain-size coarsening were based upon a single sample from each location. To support these regional observations, Perranporth, a highenergy, macro-tidal sandy beach site, was selected for repeat high resolution DGS surveys. These surveys were repeated every other month, with a total of nine DGS surveys completed within the study period. The DGS survey results were consistent with the observations from the regional physical samples. Sediments were regularly finer and poorer sorted on the upper beach than the lower beach, with an average grain size of $0.335 \mathrm{~mm}$ (medium sand) and a sorting of 0.366 (well-sorted) on the upper beach and $0.402 \mathrm{~mm}$ (medium sand) and 0.238 (very well-sorted) on the lower beach, corresponding to an average $20 \%$ increase in grain size and an improvement of $35 \%$ for sorting. Figure $4 \mathrm{~A}$ shows the locations (141 samples) and surface grain sizes for the DGS survey collected in August 2014. Across the $550 \mathrm{~m}$ by $1200 \mathrm{~m}$ survey extent, grain sizes consistently coarsened with increasing seaward distance across the intertidal. While the upper and middle beach were longshore uniform with little variation between sediments in the north and south, the lower beach showed some longshore variation. There was a slight coarsening trend towards the north caused by localised coarse (and well-sorted) patches associated with the nonuniform low-tide bar and rip morphology. Sediments found in the active channels were up to $0.1 \mathrm{~mm}(26 \%)$ coarser and considerably better sorted than sediments found on the adjacent intertidal sand bars and consistent with prior observations made by Gallagher et al. (2011) and Thorpe et al. (2014).

The results from each of the nine DGS surveys are also shown in Fig. 4, with Fig. 4B the cross-shore grain-size profiles and Fig. 4C the sorting. While the general cross-shore coarsening and improvement in sorting is observed in each of the nine surveys, the degree of difference between the upper and lower beach sediments is variable. The two occurrences of the lower beach sediments exceeding $0.45 \mathrm{~mm}$ are associated with the extreme winter storms of 2013 to 2014 (Masselink et al., 2015), where persistently large This article is protected by copyright. All rights reserved. 
(Fig. 5A, shaded) long period waves conditions drove extreme coarsening (and erosion) across the lower intertidal profile, with lower beach sediments up to $52 \%$ coarser than typical winter values. These larger grain sizes associated with the storms are not apparent in the upper beach sediments, which were only $3 \%$ coarser than typical winter values. The crossshore grain-size profiles that had a reduced contrast between the upper and lower beach sediments were collected during the lower energy summer months. Grain size increased by an average of $18.9 \%$ and sorting improved by an average $26.4 \%$, although due to the seasonal periodicity, winter sediment grain sizes increased and sorting improved by up to a maximum of $51.6 \%$ (average $32.4 \%$ ) and $64.4 \%$ (average $51.0 \%$ ), respectively. During the summer months, the maximum increase of grain size with cross-shore distance was $9.4 \%$ (average 8.3\%) and the maximum improvement in sorting was 33.3\% (average 18.3\%).

\section{THE RELATIONSHIP BETWEEN THE SPATIAL GRAIN-SIZE PATTERNS AND WAVE ENERGY DISSIPATION}

\subsection{Wave energy dissipation model}

The position and extent of the surf zone is implicitly linked to beach morphology and sediment transport. Studies in laboratory flumes (Çelikoğlu et al., 2006; Kakinoki et al., 2011; Jiang et al., 2015), have shown a consistent relationship between the sediment characteristics (grain size and sorting) and energy dissipated by breaking waves. Additionally, Reniers et al. (2013) showed that for a high-energy beach, using natural hydrodynamic and sedimentological conditions, the position of the shore break over a number of days always correlated to the maximum observed grain sizes. However, this concept has yet to be examined on a macro-tidal site across a multi-year temporal scale, which accounts for the seasonal variations and episodic storm responses.

This article is protected by copyright. All rights reserved. 
Therefore, this study compares the high resolution DGS surveys from Perranporth, with the outputs of a Battjes \& Janssen (1978) wave balance model. This model estimates the rate of wave energy dissipation (D) per unit width (1 m cross-shore spacing), simplified as:

$$
\bar{D}=\frac{\alpha}{4} Q f \rho g H_{m}^{2}
$$

where $\alpha$ is a dimensionless coefficient of magnitude $1, f$ is the wave frequency $\left(f=1 / T_{p}\right), \rho$ is the water density, $g$ the gravitational acceleration, $H_{m}$ is the depth limited wave height and $Q$ is the fraction of breaking waves $\left[Q=f\left(H_{r m s} / H_{m}\right)\right.$, where $\left.H_{r m s} \sim H_{s} / 1.4\right]$. The model estimates the dissipation of a single breaking wave (with a height denoted by $\mathrm{H}_{\mathrm{rms}}$ ) using a bore dissipation model and then combines this with a clipped-Rayleigh probability density function to estimate the dissipation of a random wave field. Only five inputs are required to successfully run the model, a value for the wave height $\left(H_{s}\right)$, peak wave period $\left(T_{p}\right)$, wave direction $\left(\theta_{p}\right)$, tidal elevation for each predictive time step (every 30 minutes) and a beach profile. The hydrodynamic data $\left(H_{s}, T_{p}, \theta_{p}\right.$ Fig. 5A, B and C) were recorded in 30-minute intervals from a nearshore Datawell directional WaveRider buoy (Datawell BV, Haarlem, The Netherlands), moored in 10 to $14 \mathrm{~m}$ water depth, $0.6 \mathrm{~km}$ offshore from Perranporth. Between 8 February 2014 and the 14 March 2014, the Perranporth wave buoy was damaged, with the gap in the time series filled in by the outputs of a local SWAN model nested within a regional wave model. This model, set up with a $12 \times 15 \mathrm{~km}$ grid and a $150 \mathrm{~m}$ node size, output twodimensional spectral data at a location coincident with the nearshore wave buoy [see Austin et al. (2012) for detailed setup conditions and model validation]. A continuous time-series of tidal elevation for each 30 minute hydrodynamic measurement was calculated via an interpolation using local tidal coefficients (Fig. 5D).

This article is protected by copyright. All rights reserved. 
Before input into the Battjes \& Janssen (1978) model, the hydrodynamic inputs $\left(H_{s}, T_{p}, \theta_{p}\right)$ were weighted using a temporally-evolving term that recognises that there is significant hysteresis, in which further change is dependent upon the antecedent conditions (Davidson et al. 2013). This weighting function can be expressed as:

$$
\gamma_{\phi}=\left[\sum_{i=1}^{2 \phi} 10^{-i / \phi}\right]^{-1} \sum_{i=1}^{2 \phi} \gamma_{i} 10^{-1 / \phi} \quad \text { Equation (3) }
$$

where $\gamma$ represents either the $H_{s}, T_{p}, \theta_{p}$ time-series and $\gamma \phi$ represents the antecedent $H_{s}, T_{p}$, $\theta_{p}$ time-series. The weighting function decays at a rate governed by $\phi$ and reaches $10 \%$ and $1 \%$ at $\phi$ and $2 \phi$ days prior to the current calculation time. Prodger et al. (2016) found, when describing temporal grain-size patterns at Perranporth over a number of years, that an optimum fit to the antecedent wave conditions were obtained with a weighting function decaying at a rate that reached $10 \%(\phi)$ of the present value at 83 days and $1 \%(2 \phi)$ at 166 days. Despite the inclusion of this antecedent term, the most recent wave conditions are still the most important, with rapid change possible if the current conditions are sufficiently different from the antecedent conditions.

Intertidal topographic surveys were collected every month from 2008 to 2016 , using an RTK-GPS (accurate to $\pm 0.03 \mathrm{~m}$ ) mounted on an all-terrain vehicle on the biggest spring low tide of the month. For the study period, a total of 22 monthly intertidal surveys were collected, with a mean interval of 24 days. The subtidal profile was measured using a Valeport MIDAS Surveyor (Valeport Limited, Totnes, UK) logging in high-frequency mode at $210 \mathrm{kH}_{\mathrm{z}}$, deployed from a $3.8 \mathrm{~m}$ Aranica RIB (Arancia Industries Limited, Auckland, New Zealand). Height corrections were provided by RTK-GPS (accurate to $\pm 0.03 \mathrm{~m}$ ), input into the MIDAS during field data collection which reduced the associated error to $\pm 0.15 \mathrm{~m}$. Subtidal bathymetry was collected along cross-shore profiles that had a $25 \mathrm{~m}$ resolution from spring low tide to the subtidal bar crest and a $50 \mathrm{~m}$ resolution offshore from the subtidal bar crest. As these subtidal surveys required wave heights to be less than $1 \mathrm{~m}$, only seven were obtained. Additionally, the timeframe between them was significantly larger than the monthly This article is protected by copyright. All rights reserved. 
intertidal surveys. For the study period, the minimum, mean and maximum spacing was 27 days, 75 days and 230 days, respectively, with the latest available collected in July 2015. Each subtidal survey was meshed with the nearest available intertidal survey and gridded at a $25 \mathrm{~m}$ resolution in both the cross-shore and alongshore directions via a quadratic loess interpolation scheme (Plant et al., 2002). This interpolation created a continuous threedimensional surface of the intertidal topography (accurate to $\pm 0.08 \mathrm{~m}$ ) and subtidal bathymetry (accurate to $\pm 0.205 \mathrm{~m}$ ) that was translated onto a local co-ordinate grid. A beach profile with a $1 \mathrm{~m}$ cross-shore spacing suitable for use with the wave dissipation model was then extracted from this surface.

Using the antecedent-weighted hydrodynamic inputs $\left(\mathrm{H}_{\mathrm{s}}, \mathrm{T}_{\mathrm{p}}, \theta_{p}\right.$ and Tidal Elevation) and the cross-shore beach profile to force the model, a dissipation value for each $1 \mathrm{~m}$ crossshore location specified by the beach profile is output. To obtain a time-averaged, antecedent-adjusted dissipation profile, the outputs from the model (every 30 mins) are integrated over $2 \phi$ days (ca 326 tidal cycles) prior to the current calculation time. A summary of the DGS sample positions, the cross-shore transect along which the grain size, sorting and elevation profiles were extracted and the origin point for the local co-ordinate grid is available in Fig. 6 and an example of an integrated dissipation profile in Fig. 7.

\subsection{Antecedent-adjusted model results}

The cross-shore coarsening in grain size and improvement in sorting noted in the DGS surveys from Perranporth was related to the hydrodynamic conditions via the BattjesJanssen 1D cross-shore wave dissipation model, using inputs which had been weighted with a temporally-evolving antecedent term. The time-averaged energy dissipation strongly correlated with grain-size and sorting profiles. Model outputs, in addition to the grain-size, sorting and beach profiles are shown in Fig. 8, with the error bars obtained using the data in Fig. 2 and are a reflection of the confidence that the digital grain-size measurements reflect the actual $D_{50}$ and sorting value.

This article is protected by copyright. All rights reserved. 
Due to the strong seasonality in wave heights, during the winter months (Fig 8A, B, F and G) the surf zone was wider, with waves breaking further offshore and dissipating increased amounts of energy across the profile. Average energy dissipated across the entire crossshore profile was $16.2 \mathrm{Wm}^{-3}$ in winter, compared to $3.9 \mathrm{Wm}^{-3}$ in summer. The increased amount of energy dissipated and wider surf zone width (average winter surf zone width $738 \mathrm{~m}$ ), were associated with the greatest variation between the upper and lower beach sediment grain sizes and sorting (Fig. 9). Although, grain size and sorting still increased with increasing distance across the intertidal zone in the calmer summer months, there was a reduced contrast between the upper and lower beach sediments. This was linked to the reduced amount of energy dissipated across a narrower surf zone (average summer surf zone width $-531 \mathrm{~m})$.

\section{DISCUSSION}

The spatial variability in grain size and sorting was assessed using both physical samples from 53 sites around the south-west peninsula of the UK and high-resolution digital grain size (DGS) surveys from Perranporth. Each of the sandy sites (49 in total) exhibited a crossshore coarsening and an improvement in sorting towards mean spring low-tide, regardless of the average $D_{50}$ size (Fig. 3). The DGS surveys supported the results from the regional physical samples, with grain size consistently increasing and sorting improving with increasing seaward distance across the intertidal in all nine surveys (Fig. 4). Due to the increased number of digital samples (mean 223) compared to the physical samples (three per site), variability can be observed at significantly higher resolution. Regardless of the underlying morphology, hydrodynamic conditions or alongshore location, grain size (and sorting) consistently increased (and improved) in the seaward direction across the intertidal zone. Additionally, the upper and middle beach face were longshore uniform, with little variation. When the beach was in a dissipative state there was also little longshore variation

This article is protected by copyright. All rights reserved. 
in the lower beach sediments. However, with the development of non-uniform bar and rip morphology there was some longshore variability in the lower beach sediments, whereby 3D bar and rip topography was associated with localised well-sorted, coarse sediment patches.

Outputs from the Battjes \& Janssen (1978) wave dissipation model indicate that the temporally-averaged, antecedent adjusted, cross-shore energy dissipated from breaking waves correlates well with the cross-shore grain size and sorting profiles (Fig. 8). Areas of high dissipation are more turbulent and will readily transport the finer sand fractions due to a lower transport threshold, either offshore, onshore or alongshore depending upon the prevailing wave, current and tidal conditions. Increased amounts of dissipation corresponded to coarser better sorted sediments on the bed. However, it is typically assumed that all sediments across the intertidal respond in the same manner to changing hydrodynamic conditions, instead the DGS survey results show that the upper and lower beach sediments exhibit different seasonal behaviour. As the sediments at the mean spring high-tide mark were only in the swash during peak spring tides, the seasonal periodicity is smaller than that displayed by sediments on the lower beach, which are submerged in the surf zone almost continuously. The cross-shore coarsening and the seasonal variability correlated with the outputs of a Battjies \& Janssen (1978) model, where the coarser, better sorted sediments on the lower beach were explained by the increased amount of energy dissipation (turbulence) preferentially removing the finer sediment fractions. The seasonal periodicity between the amount of energy dissipated on the upper beach in summer and winter was low, reflected in small variations in summer and winter sediment grain sizes and sorting values. However, on the lower beach, the larger winter storm waves break further offshore, and with more energy, than the smaller summer swell waves, prompting surface grain sizes to significantly coarsen as fines were removed. It was found that the time-averaged peak energy dissipation correlated with the location of the observed maximum grain sizes and sorting and the amount of energy dissipated adjusted the degree of coarsening and improvement in sorting between sediments on the upper and lower beach (Fig. 9). This relationship between coarse

This article is protected by copyright. All rights reserved. 
grain sizes and high breaking wave dissipation and turbulence has been shown to occur in flume studies (Çelikoğlu et al., 2006; Jiang et al., 2015), on micro-tidal (Reniers et al., 2013) and meso-tidal (Bascom, 1951) coasts and tidal-flats (Malvarez et al., 2001). Yet, this study is the first to examine this on a macro-tidal location using natural wave forcing over a relatively long temporal scale, in addition to using repeated field data for both the beach profiles and sediment characteristics. Additionally, the use of antecedent hydrodynamic inputs using a temporally-evolving weighting term (Eq. 3) has not previously been applied to spatial grain-size patterns. However, it has been used successfully in studies by Wright et al. (1985) on beach morphodynamics, Davidson et al. (2013) on shoreline change, Stokes et al. (2015) on three-dimensional sand bar evolution and Prodger et al. (2016) on temporal grainsize variability. These studies all noted improved correlations with the introduction of an antecedent term, which recognises that there is significant hysteresis where future change is dependent upon the previous conditions. By including this antecedent term, the correlation between the antecedent adjusted breaking wave dissipation and the grain size and sorting profiles were considerably improved (Fig. 8).

Currently, the DGS profiles are limited to the dry intertidal zone, as the turbulence and high suspended sediment concentrations caused by strong wave and swash conditions make clear images difficult to obtain underwater. Although, as the wave energy dissipation is modelled to reduce offshore from the subtidal bar crest, increasingly smaller fractions should be able to settle out of suspension. Therefore, grain size would begin to decrease and sorting would become poorer with increasing offshore distance from this point.

\section{CONCLUSIONS}

Using a data set of 53 beaches from around the south-west, United Kingdom, consistent spatial variations in beach sediment grain size and sorting were observed, with grain-size coarsening and sorting improving by an average of $19 \%$ and $18 \%$, respectively, in the

This article is protected by copyright. All rights reserved. 
seaward direction across the intertidal zone. High spatial resolution digital grain-size (DGS) surveys from Perranporth support these observations, with an average increase of $18.9 \%$ and $26.4 \%$ for grain size and sorting, respectively. There was a strong seasonality in the sediments on the lower beach, with winter grain sizes up to $0.12 \mathrm{~mm}(30 \%)$ coarser than the summer equivalents. This seasonality was reduced for the upper beach sediments, with only a $0.04 \mathrm{~mm}(12 \%)$ increase between summer and winter grain sizes. The increase of grain size and improvement in sorting with increasing seaward distance across the intertidal was more pronounced in the winter months, with a maximum coarsening of up to $51.6 \%$ and a $64.4 \%$ improvement in sorting. In summer months the maximum increase in grain size and increase in sorting was only $9.4 \%$ and $33.3 \%$, respectively.

Cross-shore grain-size and sorting profiles were deterministically linked to the antecedentadjusted breaking wave dissipation, with the observed maximum grain sizes and sorting corresponding to the location of peak energy dissipation. Additionally, the different seasonal behaviour shown by the upper and lower beach sediments correlated to a greater amount of energy dissipated across a wider surf zone during the winter months.

\section{ACKNOWLEDGMENTS}

The monthly intertidal surveys were generously supported by a Plymouth University Marine Institute HEIF-V grant to the Coastal Process Research Group at Plymouth University. Data is available by way of http://coastalprocesses.org.

Special recognition goes to Erwin Bergsma (2013/2014) and Olivier Burvingt (2014/2015) for their assistance with the monthly intertidal data collection, to Dr Tim Scott and Dr Tim Poate for the subtidal data collection, and to Dr Dan Buscombe for the use of his excellent digital grain size GUI, freely available from https://github.com/dbuscombe-usgs.

Finally, many thanks to Dr Edith Gallagher, Dr Heidi Wadman and one anonymous reviewer for their helpful reviews and comments that have undoubtedly improved the quality of this manuscript.

This article is protected by copyright. All rights reserved. 


\section{REFERENCES}

Abuodha, J.O.Z. (2003) Grain size distribution and composition of modern dune and beach sediments, Malindi Bay coast, Kenya. Journal of African Earth Sciences, 36, 41-54.

Austin, M.J., Scott, T.M., Russell, P.E. and Masselink, G. (2012) Rip current prediction: development, validation, and evaluation of an operational tool. Journal of coastal research, 29, 283300.

Bagnold, R.A. (1941) The physics of wind blown sand and desert dunes. Methuen, London, 265.

Barnard, P.L., Rubin, D.M., Harney, J. and Mustain, N. (2007) Field test comparison of an autocorrelation technique for determining grain size using a digital 'beachball'camera versus traditional methods. Sedimentary Geology, 201, 180-195.

Bascom, W.N. (1951) The relationship between sand size and beach-face slope. Eos, Transactions American Geophysical Union, 32, 866-874.

Battjes, J. and Janssen, J. (1978) Energy loss and set-up due to breaking of random waves. Coastal Engineering Proceedings, 1.

Buscombe, D. (2013) Transferable wavelet method for grain-size distribution from images of sediment surfaces and thin sections, and other natural granular patterns. Sedimentology, 60, 17091732.

Buscombe, D. and Masselink, G. (2006) Concepts in gravel beach dynamics. Earth-Science Reviews, 79, 33-52.

Çelikoğlu, Y., Yüksel, Y. and Kabdaşli, M.S. (2006) Cross-Shore Sorting on a Beach under Wave Action. Journal of Coastal Research, 487-501.

Davidson, M., Splinter, K. and Turner, I. (2013) A simple equilibrium model for predicting shoreline change. Coastal Engineering, 73, 191-202.

Doucette, J.S. (2002) Geometry and grain-size sorting of ripples on low-energy sandy beaches: field observations and model predictions. Sedimentology, 49, 483-503.

Evening, M. (2015) Adobe Photoshop CC for Photographers, 2015 Release. CRC Press.

Ferguson, R. and Church, M. (2004) A simple universal equation for grain settling velocity. Journal of sedimentary Research, 74, 933-937.

Folk, R.L. and Ward, W.C. (1957) Brazos River bar: a study in the significance of grain size parameters. Journal of Sedimentary Research, 27.

Gallagher, E., Wadman, H., McNinch, J., Reniers, A. and Koktas, M. (2016) A Conceptual Model for Spatial Grain Size Variability on the Surface of and within Beaches. Journal of Marine Science and Engineering, 4, 38.

This article is protected by copyright. All rights reserved. 
Gallagher, E.L., MacMahan, J., Reniers, A., Brown, J. and Thornton, E.B. (2011) Grain size variability on a rip-channeled beach. Marine Geology, 287, 43-53.

Hervouet, J.M. and Bates, P. (2000) The telemac modelling system special issue. Hydrological Processes, 14, 2207-2208.

Horn, D.P. and Walton, S.M. (2007) Spatial and temporal variations of sediment size on a mixed sand and gravel beach. Sedimentary Geology, 202, 509-528.

Jiang, C., Wu, Z., Chen, J., Deng, B. and Long, Y. (2015) Sorting and Sedimentology Character of Sandy Beach Under Wave Action. Procedia Engineering, 116, 771-777.

Kakinoki, T., Tsujjimoto, G., Yamada, F., Sakai, D. and Uno, K. (2011) Beach profile and sediment characteristics of a mixed sand beach under diurnal sea level variations. Journal of Coastal Research, 765.

Malvarez, G.C., Cooper, J. and Jackson, D. (2001) Relationships between wave-induced currents and sediment grain size on a sandy tidal-flat. Journal of Sedimentary Research, 71, 705-712.

Masselink, G., Scott, T., Poate, T., Russell, P., Davidson, M. and Conley, D. (2015) The extreme 2013/2014 winter storms: hydrodynamic forcing and coastal response along the southwest coast of England. Earth Surface Processes and Landforms.

Plant, N.G., Holland, K.T. and Puleo, J.A. (2002) Analysis of the scale of errors in nearshore bathymetric data. Marine Geology, 191, 71-86.

Prodger, S., Russell, P., Davidson, M., Miles, J. and Scott, T. (2016) Understanding and predicting the temporal variability of sediment grain size characteristics on high-energy beaches. Marine Geology, 376, 109-117.

Reniers, A., Gallagher, E., MacMahan, J., Brown, J., Rooijen, A., Thiel de Vries, J. and Prooijen, B. (2013) Observations and modeling of steep-beach grain-size variability. Journal of Geophysical Research: Oceans, 118, 577-591.

Roelvink, D., Reniers, A., Van Dongeren, A., de Vries, J.v.T., McCall, R. and Lescinski, J. (2009) Modelling storm impacts on beaches, dunes and barrier islands. Coastal engineering, 56, 1133-1152.

Rubin, D.M. (2004) A simple autocorrelation algorithm for determining grain size from digital images of sediment. Journal of Sedimentary Research, 74, 160-165.

Rubin, D.M., Chezar, H., Harney, J.N., Topping, D.J., Melis, T.S. and Sherwood, C.R. (2007) Underwater microscope for measuring spatial and temporal changes in bed-sediment grain size. Sedimentary Geology, 202, 402-408.

Thornton, E.B., MacMahan, J. and Sallenger Jr, A.H. (2007) Rip currents, mega-cusps, and eroding dunes. Marine Geology, 240, 151-167.

Thorpe, A., Miles, J., Masselink, G. and Russell, P. (2014) Bedform Dynamics in a Rip Current. Journal of Coastal Research, 700-705.

This article is protected by copyright. All rights reserved. 
Trembanis, A., Wright, L., Friedrichs, C., Green, M. and Hume, T. (2004) The effects of spatially complex inner shelf roughness on boundary layer turbulence and current and wave friction: Tairua embayment, New Zealand. Continental Shelf Research, 24, 1549-1571.

Warrick, J.A., George, D.A., Gelfenbaum, G., Ruggiero, P., Kaminsky, G.M. and Beirne, M. (2009a) Beach morphology and change along the mixed grain-size delta of the dammed Elwha River, Washington. Geomorphology, 111, 136-148.

Warrick, J.A., Rubin, D.M., Ruggiero, P., Harney, J.N., Draut, A.E. and Buscombe, D. (2009b) Cobble Cam: Grain-size measurements of sand to boulder from digital photographs and autocorrelation analyses. Earth Surface Processes and Landforms, 34, 1811-1821.

Wright, L., Short, A. and Green, M. (1985) Short-term changes in the morphodynamic states of beaches and surf zones: an empirical predictive model. Marine geology, 62, 339-364.

Figure 1. Location map of the 53 samples sites (green circles) situated around the southwest peninsula of the UK; there are 37 from the north coast and 16 from the south and east facing coast. Physical surface samples were collected from positions that related to the upper, middle and lower beach at each site in April 2014. The red square indicates Perranporth, where high-spatial resolution digital samples were collected.

Figure 2. $D_{50}$ and sorting estimates using the DGS transferable wavelet method plotted against $D_{50}$ and sorting calculated by settling tube. The dashed line shows the perfect one to one relationship and the red line shows the best fit line. Each point represents a single image, with filled circles representing images taken in the laboratory during April 2014, and open circles images taken in the field throughout 2014. Correlation coefficients $\left(r^{2}\right)$ for grain size were 0.963 and 0.951 for sorting, with a $95 \%$ confidence interval of the digital samples compared to the settling tube of $0.0084 \mathrm{~mm}$ for grain size and $0.0064 \mathrm{~mm}$ for sorting.

Figure 3. Colours indicate the percentage change between the upper and lower beach sediment samples with (A) the cross-shore improvement in grain size and (B) the crossshore improvement in sorting.

This article is protected by copyright. All rights reserved. 
Figure 4. (A) The location of the DGS samples collected in August 2014, with the colour related to $D_{50}$ size. Contours are beach elevation (every $0.5 \mathrm{~m}$ ) collected from an RTG-GPS during the DGS survey. The longshore averaged grain size (B) and sorting (C) profiles for each of the nine DGS surveys, with the beach profile in black, the summer profiles in blue and the winter profiles in red. Due to the varying low-tide elevations each grain-size and sorting profile have been interpolated onto the same local grid.

Figure 5. Hydrodynamic measurements over the study period at Perranporth, measured at the nearshore WaveRider buoy in 10 to $14 \mathrm{~m}$ water depth. Values show the average daily $\mathrm{H}_{\mathrm{s}}$ $(A), T_{p}(B)$ and $\theta_{p}(C)$, calculated from 48 measurements on a 30 minute time-step. The shaded box in (A) highlights the extreme storms during the winter of $2013 / 2014$. Grey lines in (A), (B) and (C) are outputs from a SWAN model because the wave buoy was not in operation. The tidal elevation for each 30 min time-step relative to chart datum is shown in (D).

Figure 6. The location of the digital grain-size samples (white circles), the nearshore WaveRider buoy (blue star), the cross-shore profile (intertidal in red and subtidal in blue) and the origin position for the translation to a local co-ordinate grid (yellow circle): (A) shows the plan view, and $(B)$ the profile view.

Figure 7. (A) An example of how a time-integrated dissipation profile (magenta) would be obtained across one tidal cycle at Perranporth, with an antecedent average obtained from 24 separate dissipation profiles (30 min time-step). The hydrodynamic conditions used to force the model are available in $(B)$ wave height, $(C)$ wave period, $(D)$ wave direction and $(E)$ tidal elevation.

This article is protected by copyright. All rights reserved. 
Figure 8 (A) February 2014, (B) March 2014, (C) June 2014, (D) August 2014, (E) October 2014, (F) December 2014, (G) February 2015, (H) April 2015 and (I) June 2015. In each panel, the black line represents the beach profile (relative to chart datum) extracted from the meshed intertidal and subtidal bathymetry survey, the blue dashed line the time-integrated antecedent wave energy dissipation profile, the solid red and solid yellow, the grain-size and sorting profiles respectively, from the interpolated DGS survey. Error bars represent the 95\% confidence interval of the digital method. The scales for each $\mathrm{x}$ and $\mathrm{y}$ axis were kept consistent in each subplot.

Figure 9. Time averaged energy dissipation across the length of the profile against the percentage increase in grain size $\left(A, r^{2}=0.998, p<0.01\right)$ and improvement in sorting $\left(B, r^{2}=\right.$ 0.958, $p<0.01$ ) between the upper and lower beach sediments. Time averaged surf zone width against the percentage increase in grain size $\left(C, r^{2}=0.848, p<0.05\right)$ and improvement in sorting $\left(D, r^{2}=0.904, p<0.05\right)$ between the upper and lower beach sediments.

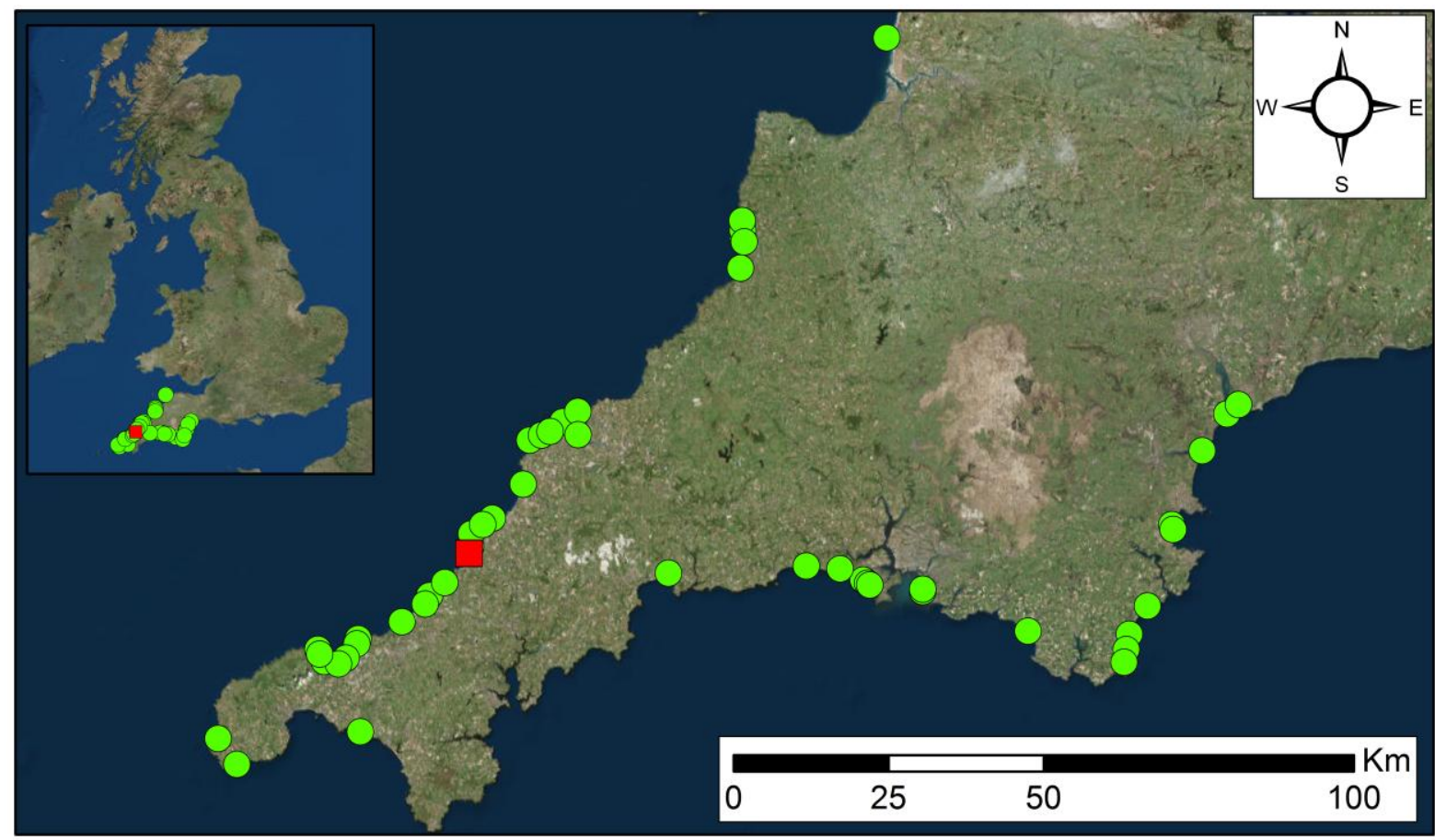

This article is protected by copyright. All rights reserved. 

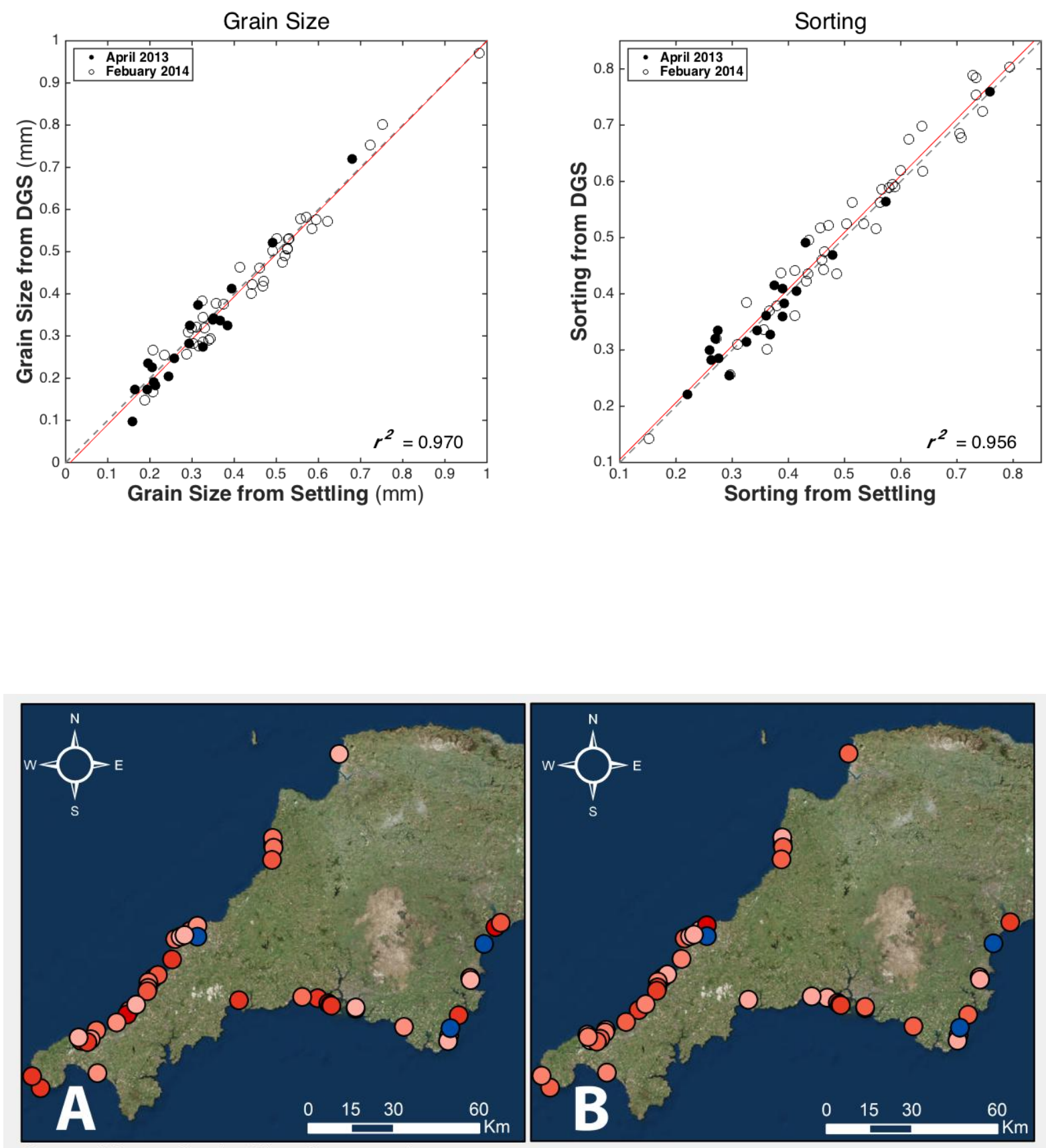

\section{Cross Shore Grain Size Coarsening}

\section{Cross Shore Sorting Improvment}
No Coarsening
○ $10-15 \%$
○ $20-25 \%$
O $0-10 \%$
○ $15-20 \%$
○ $25-30 \%$
$>30 \%$
- No Improvment
$10-15 \%$
O $0-10 \%$
- $20-25 \%$
$>>25 \%$

This article is protected by copyright. All rights reserved. 

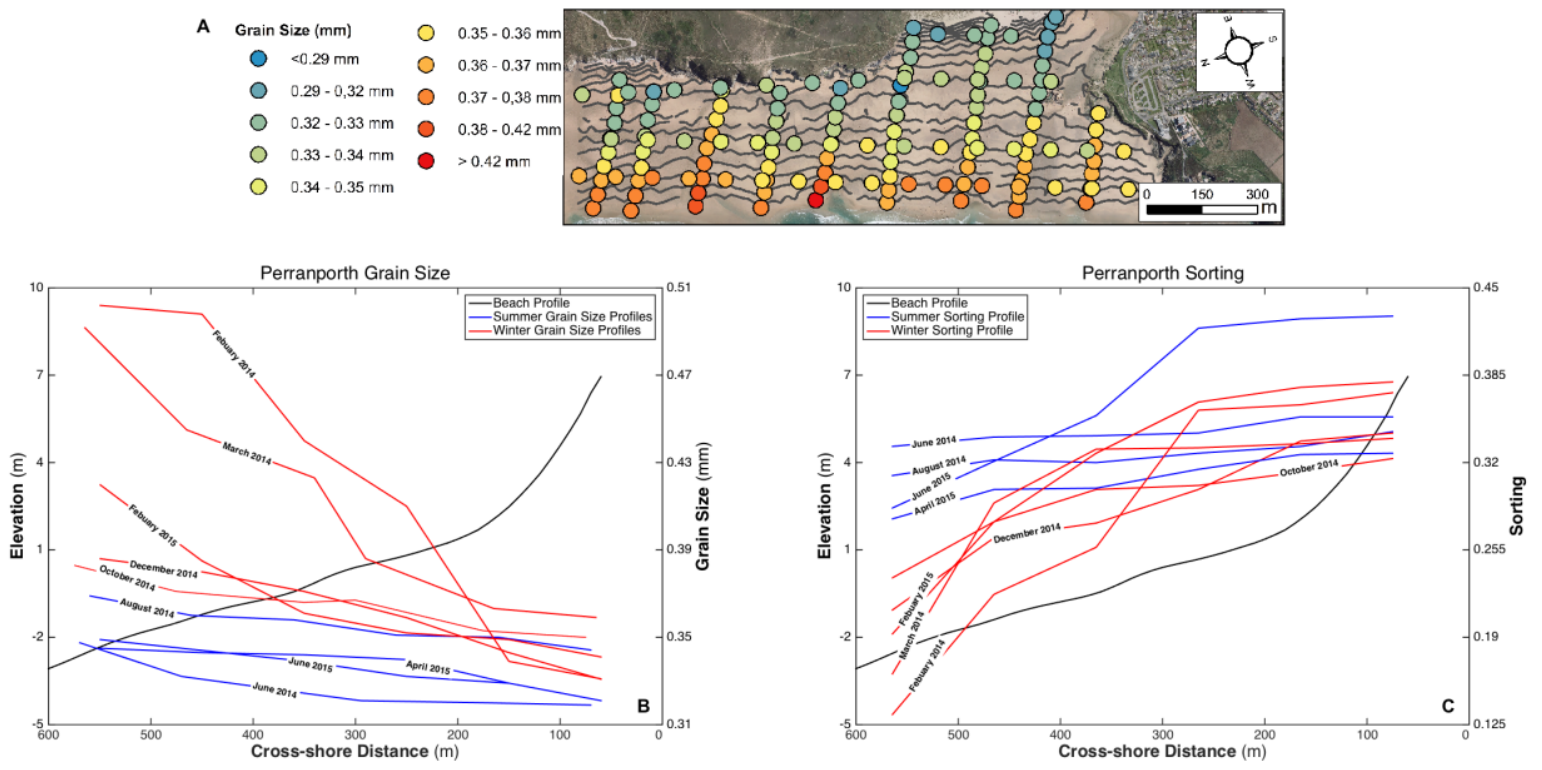

5. ${ }_{5}^{20}{ }_{10}^{15}$

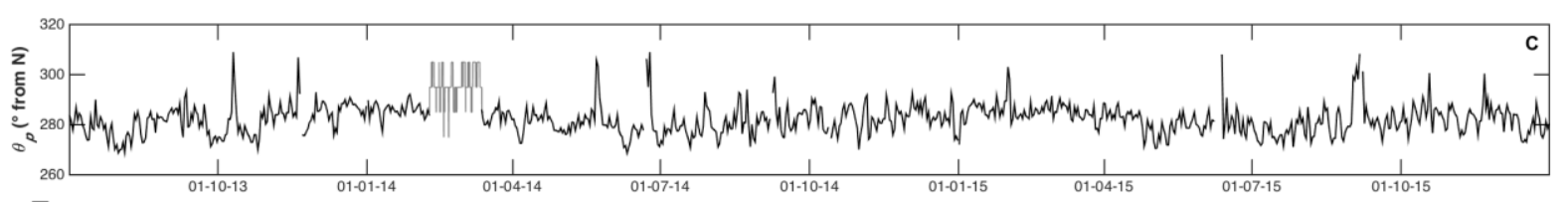

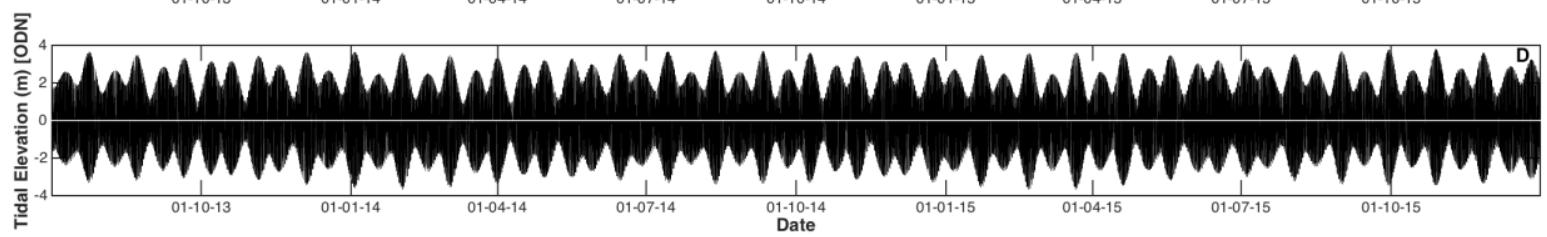

This article is protected by copyright. All rights reserved. 

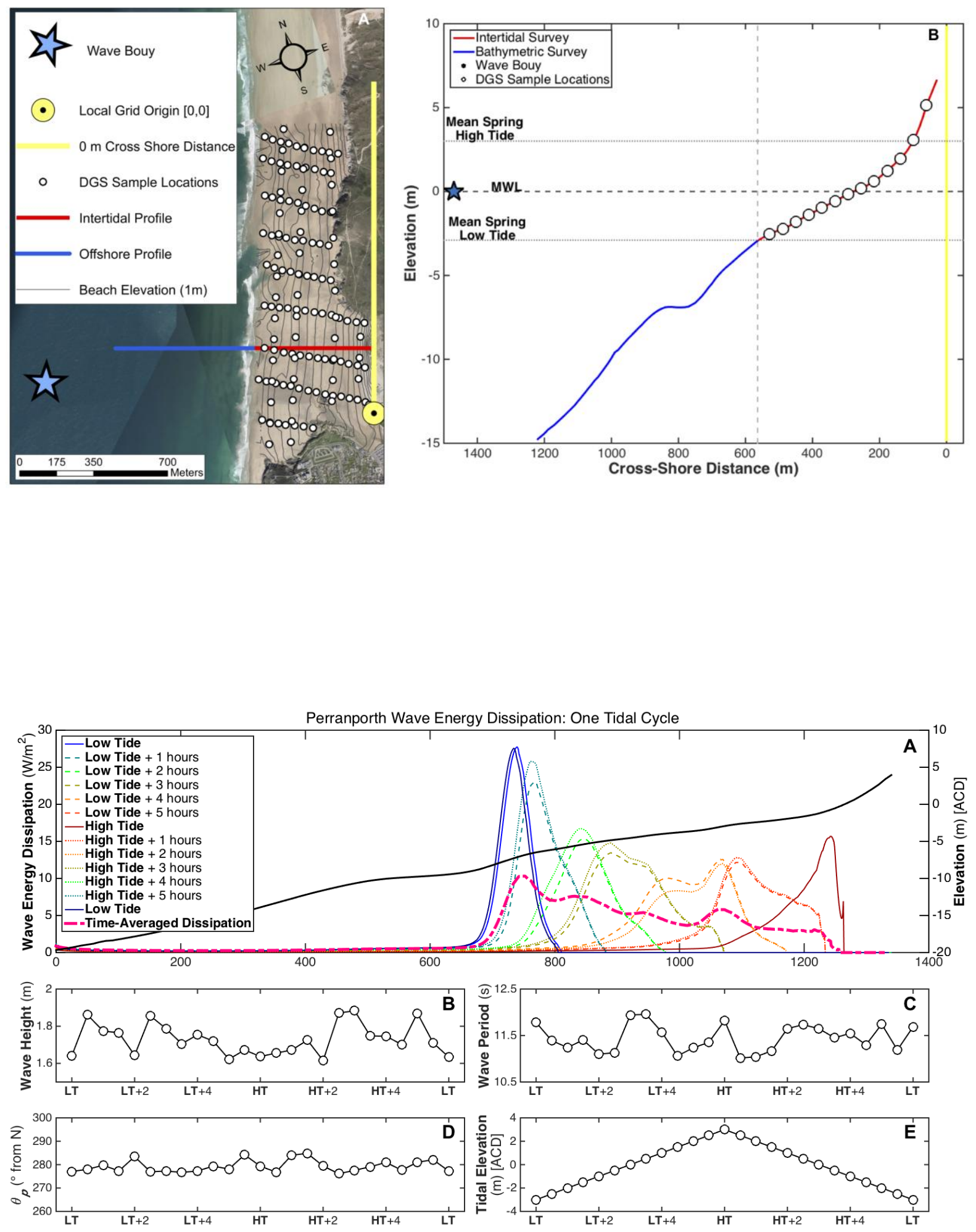

This article is protected by copyright. All rights reserved. 

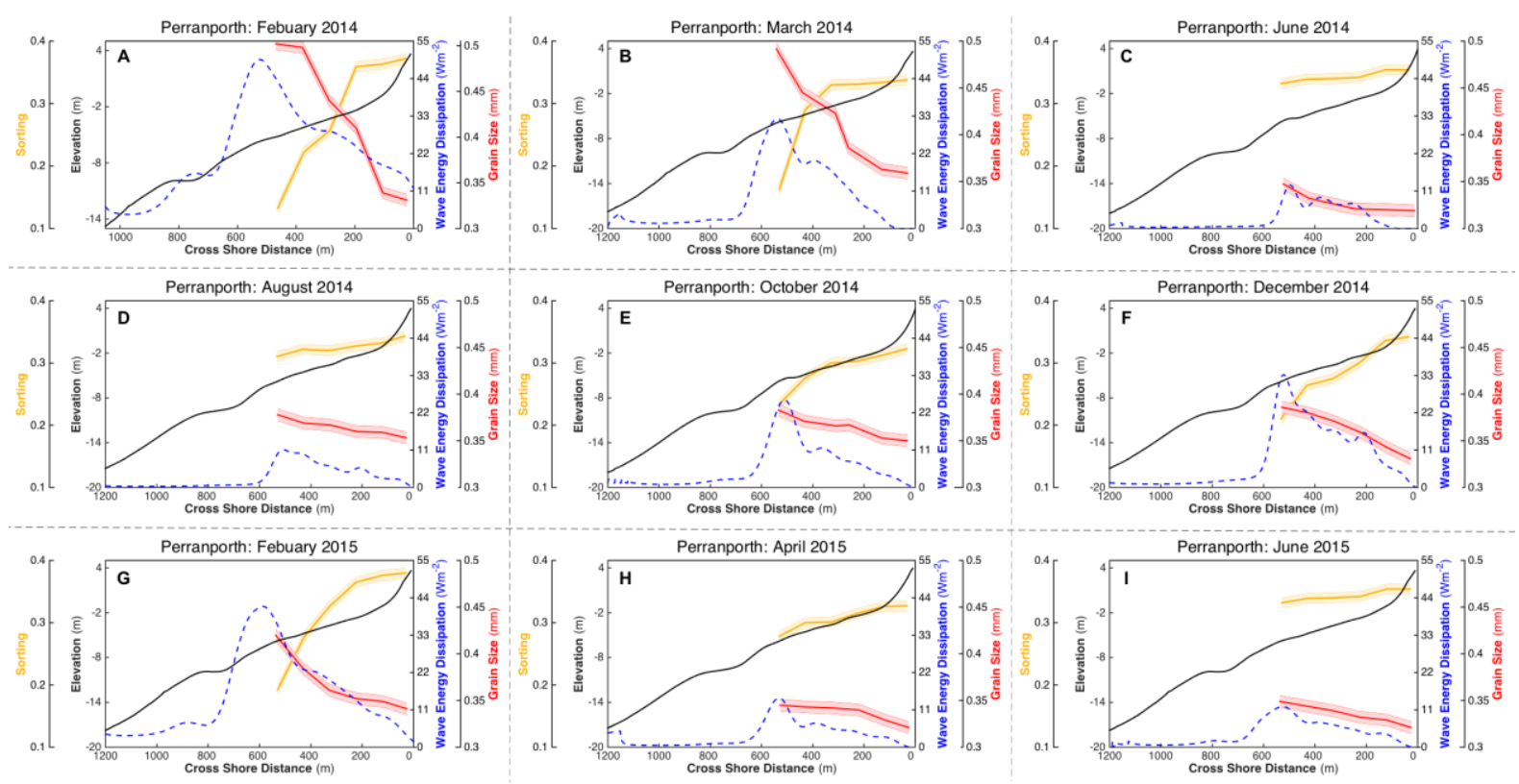

—Elevation (m - MWL) - - Time Averaged Dissipation $\left(\mathrm{Wm}^{-2}\right)$ —Grain Size $(\mathrm{mm})$ — Sorting
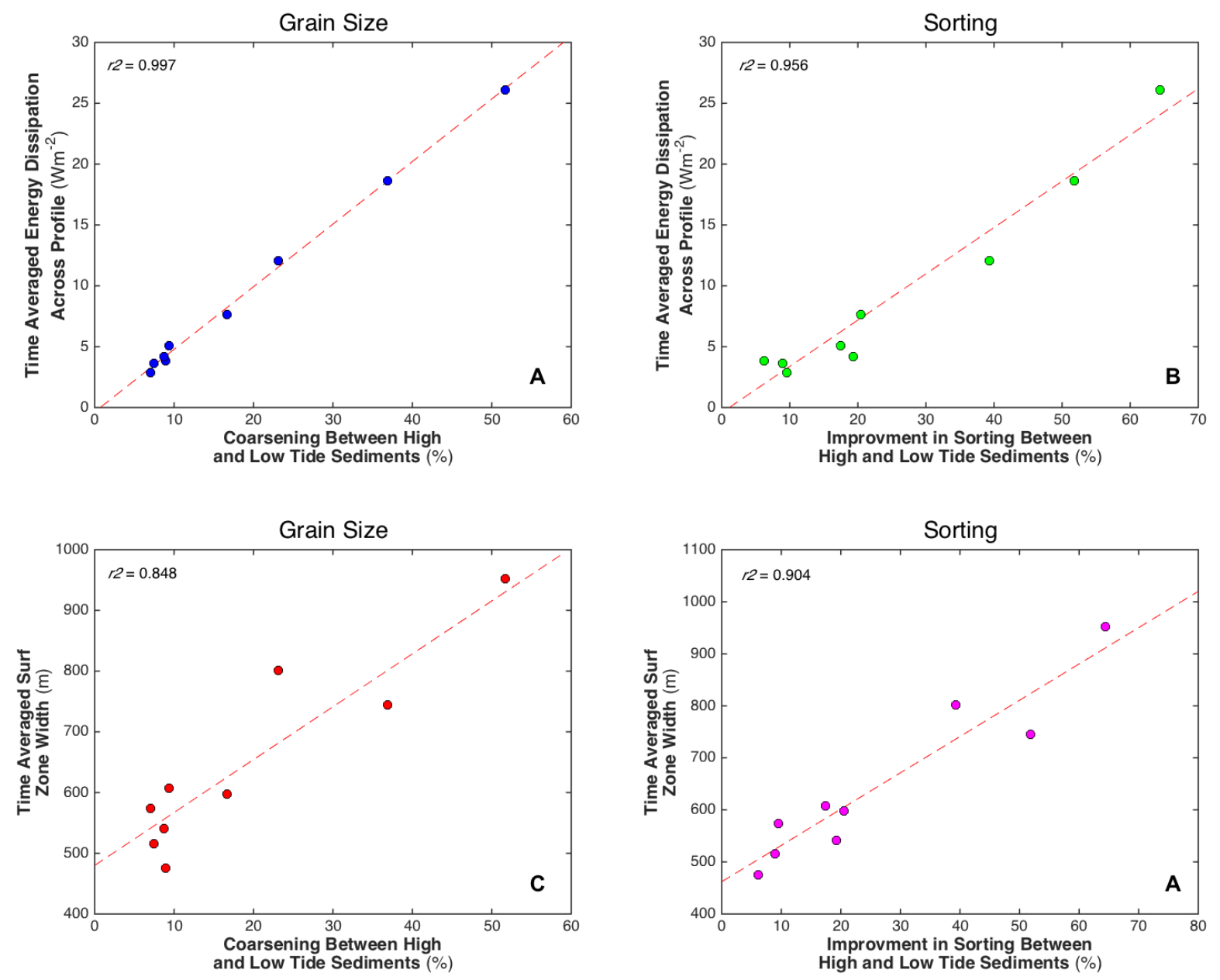

This article is protected by copyright. All rights reserved. 